\title{
The Formation of Mercapturic Acids
}

\section{DEACETYLATION OF MERCAPTURIC ACIDS BY THE RABBIT, RAT AND GUINEA PIG*}

\author{
By H. G. BRAY AND SYBIL P. JAMES \\ Physiology Department, The Medical School, University of Birmingham
}

(Received 7 August 1959)

The results of Bray, Franklin \& James (1959) suggest that the guinea pig cannot acetylate $S$-substituted L-cysteines as readily as can the rabbit or the rat. Since the failure to demonstrate acetylation might have been due to the presence of an active deacetylating system (cf. Krebs, Sykes \& Bartley, 1947) we have investigated the excretion by the rabbit, rat and guinea pig of some administered mercapturic acids and the effect of preparations of liver and kidney on these compounds. Bray, James, Thorpe \& Wasdell (1950) found that extracts of guinea-pig liver deacetylated $N$-acetylglycine more readily than did extracts of rabbit or rat liver, although the activities of extracts of guinea-pig and rabbit kidney were the same and greater than those of extracts of rat kidney. Marsden \& Young (1958) found that about $33 \%$ of a dose of 1-naphthyl-[ $\left.{ }^{35} \mathrm{~S}\right]$ mercapturic acid was excreted unchanged by rats, but, since the neutral sulphur fraction of the urine of these animals contained $81-89 \%$ of the radioactivity administered, they suggested that the urine contained some $S$-(1-naphthyl)-L-cysteine formed by metabolic deacetylation of the mercapturic acid. Parke \& Williams (1951) reported that rabbits excreted $45 \%$ of a dose of phenylmercapturic acid unchanged and $14 \%$ as $S$-phenyl-L-cysteine, but their method of determination was not recorded.

\section{MATERIALS}

The preparation and properties of $S$-butyl-L-cysteine, $N$ acetyl-S-butyl-L-cysteine and $S$-(2-chloro-4-nitrophenyl)L-cysteine were described by Bray et al. (1959), those of $S$-benzyl-L-cysteine and $N$-acetyl-S-benzyl-L-cysteine by Bray, James \& Thorpe (1958) and those of $N$-acetyl-S-(2chloro-4-nitrophenyl)-L-cysteine by Bray, James \& Thorpe (1957). p-Acetamidobenzenesulphonamide (m.p. $218^{\circ}$ ) was prepared by acetylation of $p$-aminobenzenesulphonamide with acetic anhydride.

\section{METHODS}

Animals, diet and dosage. Doe rabbits (2-3 kg. body wt.) were maintained as described by Bray, Ryman \& Thorpe (1947). Guinea pigs (300-600 g. body wt.) received $20 \mathrm{~g}$./ day of the same diet and rats (200-300 g. body wt.) $15 \mathrm{~g}$./

* Part 3: Bray, Franklin \& James (1959). day of ground rat cubes [H. C. Styles (Bewdley) Ltd.]. All animals had water ad lib. The compounds (about $0 \cdot 2 \mathrm{~g} . / \mathrm{kg}$. body wt. for rabbits and rats and $0.1 \mathrm{~g} . / \mathrm{kg}$. for guinea pigs) were administered by stomach tube as suspensions in water. No toxic effects were observed.

Tissue extracts. The animal was killed by a sharp blow on the back of the head and immediately bled. The liver and kidneys were removed and ground with sand and phosphate buffer, $\mathrm{pH} 8.1\left(0.6 \mathrm{~g}\right.$. of $\mathrm{NaH}_{2} \mathrm{PO}_{4}, 2 \mathrm{H}_{2} \mathrm{O}$ and $8.9 \mathrm{~g}$. of $\mathrm{Na}_{2} \mathrm{HPO}_{4}$ in 1 l. of water). For liver extracts $3 \mathrm{ml}$. of buffer/ g. of tissue was used and for kidney extracts $5 \mathrm{ml}$. The brei was centrifuged at $2000 \mathrm{~g}$ for $5 \mathrm{~min}$. and the supernatant retained. Reaction mixtures consisting of $30 \mathrm{ml}$. of a solution of substrate in phosphate buffer, pH 8.1 (20 mg./100 ml. for $N$-acetyl-S $S$-benzyl-L-cysteine and $N$-acetyl- $S$-(2-chloro4-nitrophenyl)-L-cysteine, $50 \mathrm{mg}$. $100 \mathrm{ml}$. for $N$-acetyl- $S$ butyl-L-cysteine and $10 \mathrm{mg} . / 100 \mathrm{ml}$. for $p$-acetamidobenzenesulphonamide) and $5 \mathrm{ml}$. of tissue extract was incubated at $37^{\circ}$ with shaking. Samples $(5 \mathrm{ml}$.) were withdrawn at intervals and deproteinized by the addition of $10 \%(w / v) \mathrm{ZnSO}_{4}, 7 \mathrm{H}_{2} \mathrm{O}(2.5 \mathrm{ml}$.) and $0.5 \mathrm{~N}-\mathrm{NaOH}(2.5 \mathrm{ml}$.). The mixture was filtered and $5 \mathrm{ml}$. samples of the filtrate were used for the determination of mercapturic acid or $p$-aminobenzenesulphonamide.

Tissue slices. These were prepared and experiments were carried out as described by Bray et al. (1959).

\section{Determination of mercapturic acids}

The methods were as described by Bray et al. (1959). SBenzylcysteine does not interfere with the determination of benzylmercapturic acid (Bray et al. 1959). The zinc hydroxide deproteinization of the tissue digests removes $S$-butylL-cysteine completely in the concentrations used so that the presence of $S$-butyl-L-cysteine in tissue extracts does not interfere with the determination of butylmercapturic acid. The intensity of the yellow given by $S$-(2-chloro-4-nitrophenyl)-L-cysteine under the conditions for the colorimetric method is less than $10 \%$ of that given by the corresponding mercapturic acid (Bray et al. 1959). This does not affect the results obtained for the mercapturic acid content of the urines since no unacetylated compound is excreted (see below). In tissue extracts which contain $\mathcal{S}$-substituted cysteine the results for mercapturic acid will be high by an amount corresponding to not more than one-tenth of the $S$-substituted cysteine present, so that the difference results in Table 2 will give an underestimate of the extent of deacetylation of $N$-acetyl-S-(2-chloro-4-nitrophenyl)-Lcysteine, which would be corrected by a factor not exceeding 1-11. Both $S$-(2-chloro-4-nitrophenyl)-L-cysteine and its $N$-acetyl derivative undergo decomposition when an alkaline solution is exposed to daylight and gradually form 
a yellow product which has an absorption spectrum identical with that finally obtained when the procedure for estimation is applied. Digests with tissue extracts prepared in the red light of a photographic dark room and incubated in the absence of light gave results in agreement with those from experiments in which these precautions were not taken. Benzylmercapturic acid and butylmercapturic acid and, if kept in the dark, $S$-(2-chloro-4-nitrophenyl)-Lcysteine were stable when incubated in phosphate buffer at pH 8.1 and $37^{\circ}$. The percentage recoveries of mercapturic acids added to liver and kidney extracts expressed as means, with ranges in parentheses and the number of experiments as superior figures, were: $N$-acetyl- $S$-benzyl-L-cysteine $99(84-101)^{18} ; \quad N$ - acetyl - $S$ - (2 - chloro - 4 - nitrophenyl - L cysteine $80(73-91)^{18} ; N$-acetyl-S-butyl-L-cysteine 101 (70$127)^{21}$.

Unabsorbed mercapturic acids. Faeces passed during $72 \mathrm{hr}$. after dosage were ground and extracted with $0.02 \mathrm{~N}$ $\mathrm{NaOH}$. The mercapturic acid in the extract was determined.

\section{Determination of other compounds}

p-Aminobenzenesulphomamide. Reaction mixtures were deproteinized with $\mathrm{ZnSO}_{4}$ and $\mathrm{NaOH}$ as described above and $p$-aminobenzenesulphonamide was determined by the method of Bratton \& Marshall (1939). p-Aminobenzenesulphonamide in urine was determined before and after hydrolysis as described by Bratton \& Marshall.

Glucosiduronic acid. The modification by Bray, Humphris, Thorpe, White \& Wood (1952) of the naphtharesorcinol method of Hanson, Mills \& Williams (1944) was used.

Ethereal sulphate. The method of Folin (1905-06) was used.

\section{Paper chromatography}

The method, solvents and detecting reagents used and the $R_{p}$ values are given by Bray et al. (1959). Under these conditions $N$-acetyl- $S$-(2-chloro-4-nitrophenyl)-L-cysteine had $R_{F} 0.89$ in solvent $A(7 \mathrm{hr}$.) and 0.46 in solvent $B$ $(16 \mathrm{hr}$.). Urines and tissue digests were applied directly to the paper.

\section{RESULTS}

Deacetylation in vivo. The results are summarized in Table 1. Paper chromatography failed to reveal the presence of the unacetylated compound or of any unidentified material detected by the Knight \& Young (1958) reagent in any urine from any of the species so that the values given for the excretion of mercapturic acid will not include any of the corresponding $S$-substituted cysteine. The amounts of unabsorbed mercapturic acids found in faeces (Table 1) suggest that the low recoveries of administered mercapturic acids should not be attributed to a failure to absorb them. The fate of that part of the mercapturic acid which is not excreted unchanged is not known. Neither $N$-acetyl-S-benzyl-Lcysteine nor $N$-acetyl-S-(2-chloro-4-nitrophenyl)L-cysteine caused a significant increase in the excretion of ethereal sulphate or glucosiduronic acid by any of the species.

Deacetylation in vitro. The results are summarized in Table 2. For all three mercapturic acids deacetylation was the only change of significant extent revealed by examination of the digests by paper chromatography; the amounts of mercapturic acids decreased and $S$-substituted cysteines appeared in amounts in general agreement with the results of the quantitative experiments. No other sulphur. containing products could be detected. The deacetylase activity of kidney extracts towards the mercapturic acids was greater than that of liver extracts. The deacetylase activity towards $p$ acetamidobenzenesulphonamide was very feeble in both tissues.

Paper chromatography of digests in which liver slices from all three species were incubated with each of the mercapturic acids gave results qualitatively the same as those obtained from liver extracts. Liver slices therefore not only acetylate $S$-substituted cysteines (Bray et al. 1959) but also deacetylate their $N$-acetyl derivatives.

Acetylation by tissue extracts. The $S$-substituted cysteines corresponding to the three mercapturic acids were incubated with tissue extracts under the

Table 1. Excretion by rabbits of administered mercapturic acids and p-acetamidobenzenesulphonamide

Urine was collected until the excretion of mercapturic acid or $p$-acetamidobenzenesulphonamide could no longer be detected (usually for at least $48 \mathrm{hr}$. after dosage). The amount excreted unchanged is expressed as a percentage of the dose. The results for urine are given as means of three experiments with ranges in parentheses.

\begin{tabular}{|c|c|c|c|c|c|c|c|c|c|}
\hline \multirow[b]{3}{*}{ Compound } & \multicolumn{3}{|c|}{ Rabbit } & \multicolumn{3}{|c|}{$\underbrace{\text { Rat }}_{\text {Rat }}$} & \multicolumn{3}{|c|}{ Guinea pig } \\
\hline & \multirow{2}{*}{$\begin{array}{l}\text { Dose } \\
\text { (mg.) }\end{array}$} & \multicolumn{2}{|c|}{ Excreted in } & \multirow{2}{*}{$\begin{array}{l}\text { Dose } \\
\text { (mg.) }\end{array}$} & \multicolumn{2}{|c|}{ Excreted in } & \multirow{2}{*}{$\begin{array}{l}\text { Dose } \\
\text { (mg.) }\end{array}$} & \multicolumn{2}{|c|}{ Excreted in } \\
\hline & & Urine & Faeces & & Urine & Faeces & & Urine & Faeces \\
\hline $\begin{array}{l}N \text {-Acetyl-S-benzyl-L- } \\
\text { cysteine }\end{array}$ & 700 & $\begin{array}{c}62 \\
(60-66)\end{array}$ & $0,0 \cdot 3$ & 70 & $\begin{array}{c}71 \\
(45-83)\end{array}$ & $0 \cdot 2,7 \cdot 0$ & 100 & $\begin{array}{c}6 \\
(3-11)\end{array}$ & $7 \cdot 5,5 \cdot 0$ \\
\hline $\begin{array}{l}N \text {-Acetyl-S-(2-chloro-4- } \\
\text { nitrophenyl)-L-cysteine }\end{array}$ & 500 & $\begin{array}{c}30 \\
(22-43)\end{array}$ & 0,0 & 70 & $\begin{array}{c}47 \\
(41-54)\end{array}$ & $0,0 \cdot 2$ & 75 & 0 & $0,16 \cdot 0$ \\
\hline$N$-Acetyl-S-butyl-L-cysteine & 600 & $\begin{array}{c}59 \\
(46-76)\end{array}$ & $0,0 \cdot 3$ & 60 & $\begin{array}{c}85 \\
(73-90)\end{array}$ & 0,0 & 90 & $\begin{array}{c}4 \\
(0-8)\end{array}$ & $0,1 \cdot 0$ \\
\hline $\begin{array}{l}p \text {-Acetamidobenzene- } \\
\text { sulphonamide* }\end{array}$ & 640 & $\begin{array}{c}68 \\
(60-73)\end{array}$ & 一 & 50 & $\begin{array}{c}71 \\
(68-74)\end{array}$ & - & 120 & $\begin{array}{c}80 \\
(78-83)\end{array}$ & 一 \\
\hline
\end{tabular}

* The average percentage of the dose excreted as $p$-aminobenzenesulphonamide by each species in $24 \mathrm{hr}$. was $3(2 \cdot 4-3 \cdot 4)$. 
conditions used for the deacetylation experiments. No significant formation of mercapturic acid from any of the cysteines in liver extracts of any of the threespecies was revealed by paper chromatography.

Stability of mercapturic acids in the alimentary canal. A fasting guinea pig (i.e. in the condition in which guinea pigs were dosed) was killed and the contents of the small and large intestine were mixed with 15 and $40 \mathrm{ml}$. of water respectively. Portions (1 ml.) of these mixtures were incubated with solutions (6 ml.) of $N$-acetyl-S-benzylcysteine $(20 \mathrm{mg}$./ $100 \mathrm{ml}$.) and of $N$-acetyl-S-butylcysteine $(50 \mathrm{mg}$./ $100 \mathrm{ml}$.) in phosphate buffer, pH 8.1 , at $37^{\circ}$. Samples of the digests were examined by paper chromatography $(a)$ immediately after mixing and (b) after incubation for $2 \mathrm{hr}$. Solvent $A$ (Bray et al. 1959) was used and spots were detected with the dichromate-silver nitrate reagent of Knight \& Young (1958). The appearance and intensity of the spots obtained in $(a)$ and $(b)$ were the same and corresponded with those given by the appropriate mercapturic acid in buffer solution. No other spots were detected with the dichromate-silver nitrate reagent.

\section{DISCUSSION}

The results in Table 1 show that both the rabbit and the rat excrete a considerable percentage of administered mercapturic acid unchanged, whereas the guinea pig excretes very little. No $S$-substituted cysteines could be detected in the urines of any of the species so that straightforward deacetylation of the mercapturic acid and excretion of the cysteine do not occur. These results suggest that in all three species the mercapturic acids undergo further modification and that the extent of this is much greater in the guinea pig than in the rabbit or the rat.Theguinea pig, however, excreted unchanged

Table 2. Deacetylation of mercapturic acids and p-acetamidobenzenesulphonamide by tissue extracts in vitro

Experimental conditions were as described in the text. The extent of deacetylation is expressed as the difference between the mercapturic acid found in the digest immediately after mixing substrate solution with tissue extract and that found after the time indicated. The difference value has been corrected by a factor derived from the quotient of the amount of mercapturic acid added divided by that found by analysis immediately after mixing the substrate solution with the tissue extract. Results are given as means with ranges in parentheses and number of experiments as superior figures.

\begin{tabular}{|c|c|c|c|}
\hline \multirow{3}{*}{$\begin{array}{c}\text { Duration of } \\
\text { incubation } \\
\text { (hr.) }\end{array}$} & \multicolumn{3}{|c|}{ Percentage of substrate deacetylated by } \\
\hline & Liver & \multicolumn{2}{|c|}{ Kidney } \\
\hline & \multicolumn{3}{|c|}{$N$-Acetyl-S-benzyl-L-cysteine } \\
\hline Rabbit & $\begin{array}{c}0 \\
(0-1)^{3}\end{array}$ & $\begin{array}{c}11 \\
(9-15)^{3}\end{array}$ & $\begin{array}{c}20 \\
(16-25)^{3}\end{array}$ \\
\hline Rat & $\begin{array}{c}7 \\
(4-13)^{3}\end{array}$ & $\begin{array}{c}16 \\
(14-19)^{3}\end{array}$ & $\begin{array}{c}27 \\
(25-28)^{3}\end{array}$ \\
\hline Guinea pig & $\begin{array}{c}17 \\
(9-23)^{3}\end{array}$ & $\begin{array}{c}44 \\
(36-51)^{3}\end{array}$ & $\begin{array}{c}80 \\
(70-90)^{3}\end{array}$ \\
\hline \multicolumn{4}{|c|}{$N$-Acetyl-S-(2-chloro-4-nitrophenyl)-L-cysteine } \\
\hline Rabbit & $\stackrel{1}{(1-1)^{3}}$ & $\begin{array}{c}9 \\
(7-11)^{3}\end{array}$ & $\begin{array}{c}18 \\
(14-24)^{3}\end{array}$ \\
\hline Rat & $\begin{array}{c}27 \\
(22-34)^{3}\end{array}$ & $\begin{array}{c}37 \\
(20-50)^{3}\end{array}$ & $\begin{array}{c}58 \\
(30-80)^{8}\end{array}$ \\
\hline Guinea pig & $\begin{array}{c}3 \\
(2-3)^{3}\end{array}$ & $\begin{array}{c}21 \\
(15-28)^{3}\end{array}$ & $\begin{array}{c}37 \\
(30-47)^{3}\end{array}$ \\
\hline \multicolumn{4}{|c|}{$N$-Acetyl-S-butyl-L-cysteine } \\
\hline Rabbit & $\begin{array}{c}27 \\
(16-40)^{3}\end{array}$ & $\begin{array}{c}29 \\
(22-36)^{3}\end{array}$ & $\begin{array}{c}61 \\
(50-70)^{3}\end{array}$ \\
\hline Rat & $\begin{array}{c}17 \\
(10-22)^{5}\end{array}$ & $\begin{array}{c}28 \\
(17-40)^{4}\end{array}$ & $\begin{array}{c}46 \\
(35-80)^{4}\end{array}$ \\
\hline Guinea pig & $\begin{array}{c}38 \\
(33-40)^{3}\end{array}$ & $\begin{array}{c}37 \\
(30-42)^{3}\end{array}$ & $\begin{array}{c}67 \\
(57-74)^{3}\end{array}$ \\
\hline \multicolumn{4}{|c|}{$p$-Acetamidobenzenesulphonamide, incubated for $7 \mathrm{hr}$. } \\
\hline Rabbit & $\begin{array}{c}2 \cdot 8 \\
(2 \cdot 7,2 \cdot 9)^{2}\end{array}$ & \multicolumn{2}{|c|}{$\begin{array}{c}0 \cdot 6 \\
(0 \cdot 5,0 \cdot 7)^{2}\end{array}$} \\
\hline Rat & $\begin{array}{c}3 \cdot 0 \\
(2 \cdot 9,3 \cdot 0)^{2}\end{array}$ & \multicolumn{2}{|c|}{$\begin{array}{c}0.9 \\
(0.9,0.9)^{2}\end{array}$} \\
\hline Guinea pig & $\begin{array}{c}4 \cdot 0 \\
(3 \cdot 0,5 \cdot 0)^{2}\end{array}$ & \multicolumn{2}{|c|}{$\begin{array}{c}1 \cdot 0 \\
(0 \cdot 9,1 \cdot 1)^{2}\end{array}$} \\
\hline
\end{tabular}


a larger amount of administered $p$-acetamidobenzenesulphonamide than did the rabbit or rat.

The experiments with tissue extracts (Table 2) suggest that the guinea-pig tissues deacetylate mercapturic acids no more readily than do those of the rabbit or the rat and there appears to be no overall correlation between results from experiments in vitro and in vivo as was observed for acetylation by Bray et al. (1959), who used tissue slices for their experiments in vitro. Tissue extracts were used for the quantitative experiments on deacetylation so as to avoid the complication of simultaneous acetylation reactions, since with tissue extracts the $S$-substituted cysteines are not acetylated to a significant extent. Whereas the guinea pig shows a correlation in that no significant proportion of administered mercapturic acid is excreted, and both liver and kidney have deacetylase activity, the deacetylase activity is of the same order as that of these tissues of the rat, which excretes unchanged a very large proportion of administered mercapturic acid. The rabbit is exceptional in that the deacetylase activity of the liver towards $N$-acetyl-S-benzyl-L-cysteine and $N$ acetyl-S-(2-chloro-4-nitrophenyl)-L-cysteine is very low, whereas towards $N$-acetyl-S-butyl-L-cysteine the deacetylase activity is as high as that in guinea-pig liver.

The results of these experiments lend little support to the view that the failure of the guinea pig to excrete significant amounts of mercapturic acid after the administration of a precursor, a $S$-substituted cysteine or the mercapturic acid itself is due to more efficient deacetylation of mercapturic acid in the liver or kidney of the guinea pig than in these tissues of the rabbit and rat. A possible explanation of the results obtained in vivo with the guinea pig would be that there was such extensive breakdown of mercapturic acids in the alimentary canal that practically no mercapturic acid was absorbed. If the breakdown products were absorbed their nature would be such that they or their metabolites escaped detection by the methods used. This explanation is a difficult one to disprove, but seems unlikely in view of the results of the experiments in which mercapturic acids were incubated with the contents of the alimentary canal. These results suggest that mercapturic acid is not extensively broken down in the gut and, since only a small proportion of a dose is found in faeces (Table 1), that the mercapturic acid is probably absorbed in vivo. The explanation of the failure of the guinea pig to excrete mercapturic acid would seem to be either that it does not acetylate to a significant extent the corresponding $S$-substituted cysteine, as suggested by Bray et al. (1959), or that it has a greater facility than has the rabbit or rat in converting mercapturic acids or $S$-substituted cysteines into products, which, if excreted in urine, have so far escaped detection.

The experiments with $p$-acetamidobenzenesulphonamide provide results from an acetylated aromatic amine for comparison with those from the three acetylated aliphatic amino compounds. All three species excreted a large proportion of administered $p$-acetamidobenzenesulphonamide unchanged and very little was excreted as $p$-aminobenzenesulphonamide. The extent of deacetylation observed in vitro was also very small. With the aromatic acetamido compound the guinea pig does not show the species difference revealed with the aliphatic acetamido compounds.

\section{SUMMARY}

1. Rabbits and rats excreted unchanged a considerable proportion of a dose of three administered mercapturic acids but guinea pigs excreted very little.

2. The excretion of deacetylated mercapturic acids was not detected.

3. All three species excreted unchanged a large proportion of a dose of $p$-acetamidobenzenesulphonamide and little was excreted as $p$-aminobenzenesulphonamide.

4. Liver and kidney extracts of all three species deacetylated the mercapturic acids and, to a small extent, $p$-acetamidobenzenesulphonamide.

5. It is concluded that it is unlikely that the small extent of the excretion of mercapturic acids by the guinea pig is the result of abnormally high deacetylase activity in guinea-pig tissues.

We wish to thank Dr W. V. Thorpe for his interest and advice and Mr P. B. Wood and Mrs B. G. Taylor for technical assistance.

\section{REFERENCES}

Bratton, A. C. \& Marshall, E. K., jun. (1939). J.biol. Chem. 128, 537.

Bray, H. G., Franklin, T. J. \& James, S. P. (1959). Biochem. J. 73, 465.

Bray, H. G., Humphris, B. G., Thorpe, W. V., White, K. \& Wood, P. B. (1952). Biochem. J. 52, 412.

Bray, H. G., James, S. P. \& Thorpe, W. V. (1957). Biochem. J. 65, 483.

Bray, H. G., James, S. P. \& Thorpe, W. V. (1958). Biochem. J. 70, 570.

Bray, H. G., James, S. P., Thorpe, W. V. \& Wasdell, M. R. (1950). Biochem. J. 47, 483.

Bray, H. G., Ryman, B. E. \& Thorpe, W. V. (1947). Biochem. J. 41, 212.

Folin, O. (1905-06). J. biol. Chem. 1, 131.

Hanson, S. W. F., Mills, G. T. \& Williams, R. T. (1944). Biochem. J. 38, 274.

Knight, R. H. \& Young, L. (1958). Biochem. J. 70, 111.

Krebs, H. A., Sykes, W. O. \& Bartley, W. C. (1947). Biochem. J. 41, 622.

Marsden, C. M. \& Young, L. (1958). Biochem. J. 69, 257. Parke, D. V.\& Williams, R.T.(1951). Biochem. J.48, xxvii. 